\title{
Realigning India's Vietnam Policy Through Cooperative Sustainable Development: a Geostrategic Counterbalancing to China in Indo-Pacific
}

\section{R. S. Aswani ${ }^{1} \cdot$ Shambhu Sajith $^{2} \cdot$ Mohammad Younus Bhat $^{3}$}

Received: 19 January 2021 / Accepted: 5 July 2021 / Published online: 13 July 2021

(C) The Author(s), under exclusive licence to Springer Nature B.V. 2021

\begin{abstract}
Vietnam is a key player in India's Act East Policy and is distressed due to China's overarching position in the South China Sea. China's expanding infrastructural investments in India's periphery have led to a regional security dilemma in Indian Ocean Region. India is steered to pursue opportunities to counter China in the latter's periphery, to which Vietnam fits as an apt ally. Hence, this paper examines the heightened need for realigning India's Vietnam policy in line with United Nations Sustainable Development Goals and explains how bilateral cooperation through sustainable trade, renewable energy production, and green investments can offer a "counter" to Chinese expansion in Indo-Pacific and its Belt and Road Initiative. This paper uses the theoretical framework of Balance of Power to enumerate how geostrategic policy decisions in India-Vietnam bilateral relations can create a "counterbalance" to the Chinese investments in India's neighborhood, especially in Pakistan.
\end{abstract}

Keywords Sustainable Development Goals · Counterbalancing · Vietnam policy · Act East Policy · Indo-Pacific

R. S. Aswani

aswani.rs@ddn.upes.ac.in

Shambhu Sajith

ssajith@ddn.upes.ac.in

Mohammad Younus Bhat younus.bhat@ddn.upes.ac.in

1 School for Life, University of Petroleum and Energy Studies, Dehradun 248007, India

2 Department of Energy Management, School of Business, University of Petroleum and Energy Studies, Dehradun 248007, India

3 Department of Economics and International Business, School of Business, University of Petroleum and Energy Studies, Dehradun 248007, India 


\section{Introduction}

In recent years, India and Vietnam have emerged as significant economies in the Indo-Pacific region, with a firm reliance on the maritime domain for sustained economic growth. While evaluating India's Vietnam policy, China emerges as a significant player due to its growth as the world's second-largest economy with increased interests in the Indian Ocean Region (henceforth IOR). The Indian Ocean is geographically located in the periphery of India and is strategically very much significant to aid India's big power ambitions in South Asia [1-3]. China's ambitions through Belt and Road (henceforth BRI), an initiative that seeks to connect Asia with Africa and Europe via land and maritime networks for improving regional integration, growing trade, and increasing economic growth, expand beyond the Pacific towards the Indian Ocean and IOR littoral countries [4-6]. Maritime Silk Route is an offshoot of BRI, encompassing maritime ambitions of China, and substantiates its ongoing and forthcoming energy trade and protecting its Sea Lines of Communication [7, 8]. In this broader context of China as a hegemon in the Indo-Pacific, this paper looks at India's Vietnam policy. Many extensive studies conducted on India-Vietnam relations discuss how both countries can cooperate on multiple fronts, defense, trade, and culture, but lacks any mention of sustainable energy trade and knowledge exchange. Hence this paper argues how the shift towards sustainability and sustainable energy trade can synergize these countries. For this study, sustainability is used as a policy concept, originating in the 1987 Brundtland Report. It indicates the needed balance between depleting natural resources and the growing aspirations of humankind [9]. The need for reliable and affordable energy is fundamental for every country and is a significant input for achieving development; the cleaner the energy source, the more sustainable the development will be [10, 11]. Most of the energy consumption in the world comes from fossil fuels, such as petroleum, oil, natural gas, and coal; nevertheless, growing energy demand is forcing countries to diversify their energy mix through new sources of energy such as wind and solar [12, 13].

In this ever-changing global energy landscape, every bilateral and multilateral relation has embedded geopolitical implications. In this background, this paper argues that policies towards improving the bilateral relationship between India and Vietnam should be drafted based on UN Sustainable Development Goals, and they need to emphasize the exchange of goods and services that can lead to a reduction of greenhouse gases and both economies becoming carbon neutral by 2050 . The desire of both countries to invest in new and renewable energy is seen in their large-scale production of wind energy. This renewed interest in renewables reduces the import of fossil fuels, reducing the maritime traffic in the IOR and the Pacific, reducing the threats imposed on energy security. Vietnam has a booming offshore wind penetration in its energy mix, and though India has already notified "National Offshore Wind Energy Policy" in 2015, it's yet to be operational [2]. Similarly, India is the world's fourth-largest producer of onshore wind energy, and Vietnam has considerable wind resources. The investments in 
renewables between India and Vietnam should encourage the smooth transfer of knowledge, technology, and best practices. Such policies should be developed by careful consultation with countries, which have excelled in applying renewable energy technologies.

India has $38.78 \mathrm{GW}$ of installed wind energy capacity. A large part of its capacity is generated from the Southern state of Tamil Nadu and Karnataka and the Western state of Gujrat and Maharashtra. The rapidly declining cost of wind power in India indicates the potential for further growth in the sector. The union government has announced guidelines for tariff-based auction, minimizing the risk and bringing in clarity for the developers [14]. Vietnam's wind power potential is significantly higher than Cambodia, Thailand, and Laos. Vietnam's wind potential is higher in the central coastal regions [15]. However, Vietnam's wind energy contributes roughly around 1\% (597 MW) of total energy production [16]. India has recently earned the fifth position in the global ranking of solar power generation, while Vietnam is trailing behind with hardly any production. India is leading the International Solar Alliance with France and promotes sharing advanced technologies through a political economy approach to gain eminence in solar power generation $[17,18]$. With 50 $\mathrm{GW}$ of installed capacity, India has become the fifth-largest hydropower sector globally, and Vietnam has an ever-growing hydropower sector. China, an upper riverine country, is the world's largest investor and builder of mega-dam projects. Many studies indicate severe environmental damages to Vietnam, potentially destabilizing its national growth, affecting fish migrations, river hydrology, and sediment transfers $[19,20]$. The South China Sea (henceforth SCS) is a substantial contentious zone, geopolitically sensitive due to Chinese aggressive SCS policies, such as building artificial islands, claiming sovereignty over the entire region, and militarization the area [21, 22]. Vietnam has called for restraint in SCS after its long standoff with China, and the Philippines has taken China to the United Nations Convention on the Law of the Sea (UNCLOS) [23, 24].

India finds these issues geopolitically similar to China's actions in its backyard. China has encircled India in IOR through a strategy that Western scholars named as String of Pearls, a line of activities building naval bases and submarines, creating an imbalance in IOR security architecture [8], while IOR is considered as India's sphere of influence [25, 26]. Akin to the debt trap diplomacy card China played in Hambantota, Sri Lanka, the investments in China-Pakistan Economic Corridor (CPEC) is identified as a game-changer in South Asia's emerging economies, though intended to boost trade, its investments changed power dynamics in terms of politics, internal situation, and inter-country alliances [27]. China claims that CPEC could boost economic avenues for Pakistan and integrate regional economic trade between South Asia, East Asia, West Asia, and Central Asia [28]. China also has many ongoing infrastructural projects as part of BRI in Africa, Seychelles, and the Maldives. Unlike other countries in India's neighborhood, India and Pakistan relations are weighed down due to a violent partition in 1947 and are characterized by mutual mistrust and suspicion. Hence, constructing Gwadar port and investing in CPEC gives China access to the energy-rich Persian Gulf region [29]. With Chinese investments in Pakistan exceeding $\$ 70$ billion, it is predicted to have substantial environmental impacts in South Asia and drive Pakistan to a debt diplomacy 
trap [30]. Conversely, CPEC is deliberated as China's strategic move to overcome its Malacca dilemma and building ports such as Gwadar and Hambantota to serve China's military and security interests [31]. However, China argues that its actions in the Indian Ocean are purely economically motivated and seldom strategic [4].

China's BRI strategies and expanding hegemonic influence in Indo-Pacific are considered a threat to global security in general, and Indo-Pacific in particular [32]. Hence, India's Vietnam policy, embedded within its Act East Policy, aims to tap this veiled potential to primarily aid Vietnam to build its economy and collaborate as a geostrategic ally, to offer a counterbalance to Chinese expansion in Indo-Pacific. India aims to build Vietnam as an ally in Southeast Asia, similar to what Pakistan is for China in its periphery. There are abundant studies conducted enumerating how India and Vietnam can offer a partnership in Defence, Trade, etc., to build their bilateral relations. Many scholars have studied India's Vietnam policy and stressed the significance of India-Vietnam relations in the existing literature. Jha [33] argues India has to identify additional potential areas of cooperation to strengthen the relationship with Vietnam in the wake of changing geostrategic dynamics. Binh [34] analyzed India-Vietnam relations after a strategic partnership in 2007 to promote trade and investment cooperation. Vo [35] argues the strong maritime cooperation of India-Vietnam in the context of the increase in security challenges in SCS, threats in freedom of navigation, and piracy and terrorism. This will further contribute towards shaping a safe and secure Indo-Pacific region [36]. Nga [37] examined the new developments in the India-Vietnam relations after Prime Minister Narendra Modi visited Vietnam in 2016; political consensus has resulted in growth in defense and economic ties. Vinh [38] analyzed the importance of India in Vietnam's foreign policy and examined the relation in strategic politics, defense, and security with the guidance of political documents by the Communist Party of Vietnam. However, none of the studies have addressed the issues relating to sustainable cooperation between India and Vietnam, and this gap is filled through this paper.

Due to the scarcity of research on how both India and Vietnam can build partnerships in line with United Nations Sustainable Development Goals, this study examines how sustainable energy practices and sustainable trade can become the significant backbone of India's Vietnam policy. The aim of the paper, thus, is to provide a sustainable direction to the growing bilateral ties between India and Vietnam. This paper acknowledges that the increasing Chinese investments in BRI have raised questions on sustainability. The mega infrastructure projects connecting 70 countries are predicted to increase investments in fossil fuels, thereby raising the global carbon emissions [39-41]. The biodiversity loss and environmental degradation caused by this ambitious plan would lead to an ecological disaster in the IndoPacific region, and the potential bilateral-multilateral arrangements being organized to counter the ill impacts of BRI ought to adopt Sustainable Development Goals as their founding principle for a balanced, sustainable Asia [42]. This paper uses the theoretical framework of Balance of Power. It enumerates how geostrategic policy decisions in India-Vietnam bilateral relations can create a "counterbalance" to the Chinese investments in India's neighborhood, especially in Pakistan.

This paper will guide the policymakers to lean towards Sustainable Development Goals in framing bilateral policies between India and Vietnam. The production 
and trade in the countries would be encouraged to shift towards greener and cleaner paths reducing the emission and reaching climate goals. The remainder of the paper is structured as follows. The "Underpinning Theory" section visits the theory that guides the research. The "BRI and Security Dilemma in Indo-Pacific" section describes BRI and security dilemma in the Indo-Pacific region, the "Sagar and the New Power Dynamics in Asia" section talks about SAGAR and new power dynamics, and the "India's Vietnam Policy: as a Counterbalancing Strategy" section proposes India's Vietnam Policy as a counterbalancing strategy. The "Cooperative Sustainable Development as a Tool to Counterbalance" Sect. 6 states the importance of cooperative sustainable development as a tool for counterbalancing. The "Trade and Economic Cooperation: Opportunities and Challenges" section depicts challenges and opportunities in India-Vietnam trade and cooperation, and finally, the "Conclusion" section concludes the study.

\section{Underpinning Theory}

This paper uses the Realist prism to study the existing power relationships in IndoPacific and employs the most popular Realist concept of Balance of Power (BOP) to understand the emerging geostrategic situation in the region. The doctrine of BOP has evolved over the years, and A.F. Pollard provides both a pre nineteenth-century meaning of BOP as "states cooperating to maintain equilibrium" to post-nineteenthcentury transformation of its meaning to "two forces balancing against one another" $[43,44]$. In either of its meaning, the intent behind establishing BOP is simple, i.e., achieving peace and maintaining security. A lack of balance characterizes the current geopolitical scenario in Indo-Pacific, and the current affairs are smeared by fear, suspicion, and mistrust. China's hegemonic expansion in the South China Sea and rapid militarization of the zone, coupled with the US interest in the Asia Pacific revitalizing alliances with Southeast Asian countries, have created a change in power distribution. Other major powers such as Japan, Australia, and some European Countries have geopolitical ambitions in Indo-pacific due to its role in energy trade leading to manipulation of power relationships with smaller countries in the Association of Southeast Asian Nations (ASEAN). India has big power ambitions in the Indian Ocean and considers it India's backyard, and hence, India views Chinese BRI activities in IOR littorals as dangerous to its aspirations. Thus, in short, power is unequally distributed in Indo-Pacific and can lead to the likelihood of war.

Hence, to bring an equal distribution of power in international politics, Alliances and Counter Alliances are created to generate power equilibrium. Alliances are ways in which countries come together, formally or informally, with common defense, economic, environmental, social, or political goals. Alliances augment the strengths of their constituent States vis-a-vis the opponent States. In this study, the alliance, which led to generating the power imbalance in Indo-Pacific is the China-Pakistan coalition and allied strategic developments in the Indian Ocean and SCS. Any agreement that affects the relative power of the antagonists affects the distribution of power. In this study, China is expanding its sphere of influence in Southeast Asia, and China, a Pacific Ocean littoral, building strategic relations with Pakistan is an 
alliance leading to an imbalance in Asia. This imbalance leads to a security dilemma in India, which recently had two stand-offs with China in Dokhlam and Ladakh, leading to violent scuffles and a few deaths of soldiers. These situations have repercussions in the Indian Ocean, affecting the sea lines, and influence India's bilateral ties with countries in the Chinese periphery, prompting India to enter into Counter Alliances, through bilateral relations and multilateral treaties.

India's forage for a potential partner in China's periphery, i.e., Southeast Asia, ends with Vietnam, as the latter has been pulled into China's economic and military orbit and wants to break open. Vietnam and India enjoy historical ties and cultural relations and can offer a unique partnership. This paper examines how India and Vietnam can form a counterbalance to China-Pakistan by building a partnership based on sustainable cooperative mechanisms, in line with the UN Sustainable Development Goals. Within this theoretical framework of Alliances and Counter Alliances, we examine how India needs to realign its historical and cultural ties with Vietnam through new areas of cooperation, such as renewable energy, sustainable trade, science and technology, and environmental protection.

The shift in the balance of power in the region and the prospective policies has to be strategic in traditional terms and futuristic by accommodating innovative and new sustainable practices. India and Vietnam are natural partners in Indo-Pacific due to their rich cultural heritage and can counterbalance China's globe bridging strategy in the region by introducing sustainable trade practices. This bilateral relationship could become an ideal model through open borders without trade barriers such as customs and tax duties and protective regimens. Increasing the investments in new and renewable energy and encouraging the transfer of knowledge, technology, and best practices to meet cleaner production ambitions also helps build a dynamic bilateral relationship. As depicted in the figure below, these theories have a high significance in understanding international relations and politics.

\section{BRI and Security Dilemma in Indo-Pacific}

Belt and Road initiative (BRI), also known as One Belt One Road (OBOR), formerly in English, is a global infrastructure project connecting 65 countries adopted by the Chinese government in 2013. "Belt" refers to the "Silk Road Economic Belt" spans across landlocked Central Asia through roads and rail. "Road" stands for the twenty-first-century maritime silk route that connects Southeast Asia to South Asia, to the Middle East, and the African continent through the Indo-Pacific sea route. BRI is vital for China's economic advancements, energy security, maritime, and geopolitical interests [45]. If the BRI becomes a reality, it will enhance China's geopolitical and economic importance bringing China to the regional network of production processes [4]. The BRI intends to strengthen regional connectivity, cooperation, and improved economic growth financed by multilateral financial instruments [46]. BRI calls for an inclusive model based on mutual benefit and learning for sustainable cooperation on a foundation of peaceful coexistence with sovereign states [46]. This open platform could improve the collaboration between Asia, Africa, and 
Europe and the modernization and reduction of poverty in the emerging economies [47]. The majority of BRI countries are classified as developing countries with a rapidly growing emerging market; the region is home to two-thirds of the world's population and generates one-third of global GDP. This region is estimated to contribute roughly 50\% to the global economy between 2015 and 2030 [39]. According to empirical studies, China and BRI countries have grown $8 \%$ more than non-BRI countries [48]. However, China's BRI has come across significant criticisms, first, by frustrating the USA with BRI as a soft balancing vehicle. Second, it promotes alternative ideas and norms, fostering the legitimacy of its rising power. Third, by forming a bargaining coalition through its financial institutions [45].

China's progress with BRI in Southeast Asia is slow, owing to the reservations that some of the ASEAN countries kept on BRI and alternative infrastructure initiatives proposed by other major players in Southeast Asia. ASEAN countries are skeptical of China's ability to deliver the promises on BRI projects [49, 50]. The South China Sea dispute has not helped China build a strong reputation among the ASEAN. The USA has remained engaged in the region through multilateral and bilateral ties to prevent China's ambition to challenge the regional order [45]. China's BRI project that connects South Asia and Southeast Asia through Bangladesh-China-India-Myanmar Economic Corridor is unlikely to occur due to the trust deficit in the Sino-Indian relationship [7, 51]. China's progress in BRI has pushed India into taking an active regional approach. India has renewed interest in the Bay of Bengal Initiative for Multi-Sectoral Technical and Economic Cooperation (BIMSTEC); apart from the South Asian Association of Regional Cooperation (SAARC), BIMSTEC includes two South Asian countries. India tries to improve the connectivity with the ASEAN countries to realign the power shift in the region; this includes ongoing India-Myanmar-Thailand trilateral highway (IMTTH) and Asian Highway Network. The IMTTH will be extended to Laos, Cambodia, and Vietnam [52]. India also initiated Mekong-India Economic Corridor, connecting Indian ports to Myanmar (Sittwe Port) [53].

India is suspicious about China's BRI and considers it a strategic initiative to transform China's current economic stature into diplomatic influences [52, 54]. Though initially, Vietnam approached BRI with caution, eventually, Hanoi had to join the BRI, not to be left alone from the regional connectivity strategies adopted by Beijing [55]. BRI has left Hanoi with two options to align strongly with the USA (considering China's expansionist behavior in the South China Sea) or maintain a hedging posture. If BRI proves successful, then Vietnam would be influenced to opt for the second option [56]. Several studies have looked into the counterbalancing of growing China's economic and military presence in the literature on the balance of power. India-US partnership to secure the former's strategic interest [57]. Japan-Australia security cooperation in the multilateral and bilateral contexts could reshape the power balance after the vacuum left by the decline of the US power [58]. India struggles to match China's military and economic strength; thus, the two choices are either to align with the threat (bandwagon) of China or to align with another great power to counter the threat [57]. 


\section{Sagar and the New Power Dynamics in Asia}

In 2015, the Indian Prime Minister made public his vision of the Indian Ocean through "SAGAR" (Ocean in Sanskrit) - an acronym for "Security and Growth for All in the Region," which is an all-encompassing program to deepen India's relationship with its maritime neighbors. However, the Government of India has not released any official document detailing the particulars of this vision, except its continued usage in speeches by Foreign Ministry officials [59]. In 2018 at the Shangri La Dialogue in Singapore and 2019 at the East Asia Summit in Bangkok, Prime Minister Modi took the idea of SAGAR further and announced the "Indo-Pacific Oceans' Initiative" to support the building of a rules-based regional architecture resting on seven pillars. The pillars are maritime security; maritime ecology; maritime resources; capacity building/resource sharing; disaster risk reduction and management; science, technology, academic cooperation; and trade connectivity/transport.

Though it is evident that SAGAR actively aspires to pursue strategic and economic interests specifically in the IOR, India's growing geopolitical interests in the Indo-Pacific is apparent through Mission SAGAR, the Humanitarian Assistance, and Disaster Relief (HADR) measures across the South China Sea, especially with adaptive measures towards COVID-19. Indian Naval Ship was deployed to Maldives, Mauritius, Madagascar, Comoros, and Seychelles to deliver coronavirus-related assistance. At their request, Rapid Response Medical Teams were deployed by India to help Maldives, Kuwait, Mauritius, and Comoros deal with the pandemic [59]. The strategic perspective of Mission SAGAR cannot be ignored as India aims to strengthen its maritime relationship with Southeast Asian countries in general and Vietnam in particular. As part of reaching out to Southeast Asia, through Mission SAGAR, Indian Naval Ship INS Kiltan delivered 15 tons of flood relief material containing 3,000 flood relief kits for Vietnam's Steering Committee for NDPC (National Disaster Prevention and Control) in December 2020. This reiterates India's position as a dependable partner and the Indian Navy as the preferred security partner and first responder [59]. The same HADR support has been extended to the flood-affected regions of Cambodia, indicating how India wants to offer its presence as an "ally" to countries in the South China Sea. Though Indian Navy's Mission SAGAR depicts the picture of a "helping oriented India," an in-depth analysis of the route of the mission indicates the wider goal of India to reach out to the smaller islands and Indian Ocean littorals, which are essential partners in China's Maritime Silk Route.

\section{India's Vietnam Policy: as a Counterbalancing Strategy}

Vietnam is a key player in India's Act East Policy. It has backed India's attempts to obtain a protuberant role in ASEAN as possible counterweights to growing Chinese assertion in the region. Vietnam is the current country coordinator for 
India in ASEAN, signaling the emergent relations between both countries. Vietnam is also rising as a core partner of India in various sub-regional, regional, and multilateral forums, as immediately after Vietnam is voted as a non-permanent member in the United Nations, it has reaffirmed its support for India's bid for permanent membership in the Security Council of UN [36]. Vietnam was one of the worst affected countries during the Cold War times. India was a strong supporter through all its testing times, and India was one of the first countries to recognize the first independent Vietnamese government. India granted Most Favored Nation status to Vietnam in 1975. In 1979, Vietnam faced a blow again due to a Chinese incursion into their territory and annexation of Hanoi. In 1962, China attacked India and annexed Indian territories in the Northeast (Arunachal Pradesh is still a contentious zone between India and China), and thus India's relationship with Vietnam becomes distinctive. India plays a leading role in the IOR, while Vietnam holds an important geopolitical position in the Pacific region. They are facing similar opportunities and challenges. Both are located in strongly developing regions, and they need to make use of this opportunity by enhancing cooperation and mutual support to grow more rapidly and sustainably.

Given the historical relationship and mutual trust both countries nourish, it is only natural that the bilateral relations would progress on political, strategic, and economic levels. Until recently, the focus of India's Vietnam policy was their shared cultural and civilizational linkages and building soft power relations. Soft power techniques are widely used to attract and shape foreign relations through attraction and appeal [60]. Even though culture and historical associations can act as catalysts to boost a strategic partnership, it alone cannot strengthen the relationship forever. The scope for widening these relations is abundant, and it needs to start with broadening the weakest link in India-Vietnam relations, i.e., the economic ties. Though trade is an economic concept, it is highly used as a diplomatic tool, and every trade relation has strategic underpinnings. Growing trade sanctions against countries antagonistic to one's political ideas and policies is an example of this. The advancement of the India-Vietnam strategic partnership began in the year 2007, and its culmination into a comprehensive strategic partnership has defined their relationship as intense and profound, covering multiple realms including security, commerce, trade, $R \& D$, technology, health, education, tourism, culture, and connectivity. Bilateral ties between both countries have strengthened in recent years, following high-level diplomatic exchanges, and have witnessed a shared focus on regional security issues, trade, and commerce, with an increasing emphasis on energy import-export and knowledge sharing. Liberalization of both economies in the 1990s has also significantly contributed to the sudden heave in each other's economic interests. India's many heightened exchanges with Vietnam, topped by Prime Minister Narendra Modi's two visits, one in September 2016 and another in September 2018, show India's significant measures to build a reliable partnership with Vietnam [37].

\section{Defence and Security}

Defense cooperation has been one of the most significant pillars of the Comprehensive Strategic Partnership (2016), through which India and Vietnam agreed to 
strengthen their strategic partnership in unity with India's Indo-Pacific Oceans Initiative (IPOI) and ASEAN's viewpoint on Indo-Pacific, both aligning to achieve shared security, prosperity, and growth for all in the region. An implementing arrangement was created between the Department of Defence Production, Ministry of Defence, India, and General Department of Defence Industry, Ministry of National Defence, Vietnam, to promote cooperation between the defense industries of the two countries [59]. To facilitate setting up of IT infrastructure at the Army Software Park in Telecommunications University, Nha Trang, with provision for training and services in the field of software applications, an agreement for 5 million dollars Indian Grant Assistance for Army Software Park at National Telecommunications University, Nha Trang, Vietnam, was concluded. This agreement was between the Embassy of India, Hanoi, and Telecommunications University, Ministry of National Defence, Vietnam. Further to this, an implementing arrangement for the Centre for United Nations Peacekeeping Operations was fashioned to identify specific activities for developing cooperation in UN Peacekeeping between India and Vietnam Department of Peacekeeping Operations for Cooperation in the United Nations Peacekeeping [59].

The defense cooperation agreement between India and Vietnam concluded in formal Defense Protocol, 2000, details that, "regular exchange of intelligence, joint coastguard training to combat piracy, jungle warfare and counterinsurgency training for the Indian army, repair of Vietnamese aircraft and helicopters, training of Vietnamese pilots, and Indian assistance on small and medium arms production" [61]. India's Multi-National Naval Exercise (MILAN) that includes Vietnam is another significant multilateral maritime cooperative agreement between both countries. Access to Nha Trang port, provided to the Indian Navy in 2015, is another major step in enhancing the naval cooperation between India and Vietnam. New Delhi now trains 500 Vietnamese sailors in submarine combat and transfer medium-sized naval warships and cruise missiles to Hanoi [62]. August 1, 2019, witnessed an extension of this maritime cooperation when India's L\&T's Shipbuilding near Chennai launched a project to build 12 high-speed vessels for the Vietnam Border Guard Force, thereby initiating an India-Vietnam Patrol Vessel Project. As part of efforts to boost maritime cooperation between the two countries, in December 2020, India and Vietnam steered a two-day Passes (Passage Exercise) in the South China Sea. The government of India extended a 100 million dollar Defence Line of Credit to Vietnam for implementation of the High-Speed Guard Boat (HSGB) Manufacturing Project for Vietnam Border Guard Command. It also handed over one completed HSGB to Vietnam, launched two HSGBs to be manufactured in India, and keel laying seven HSGBs to be manufactured in Vietnam [59]. The navies are also cooperating on fixing the environmental trepidations in their coasts, such as coral reef erosion, water pollution, turbidity, and loss of the marine ecosystem, offering a unique platform for climate change based inter-regional cooperation.

In addition, Project Mausam (meaning seasons) is a pioneering project by the Ministry of Culture, to be implemented by Indira Gandhi National Centre for the Arts (IGNCA), New Delhi, as the nodal coordinating agency with the support of the Archeological Survey of India and National Museum as associate bodies. It examines vital processes and phenomena that link different parts of the Indian Ocean 
littoral and those that connect the coastal centers to their hinterlands, extending from East Africa, the Arabian Peninsula, the Indian subcontinent, and Sri Lanka to the Southeast Asian archipelago. This project aims to build potential economic relations through the Indian Ocean to answer the Maritime Silk Route ambitions of the BRI $[3,63]$.

\section{Cooperative Sustainable Development as a Tool to Counterbalance}

Vietnam is highly vulnerable to climate change due to its geological location, which prompted them to diversify its investments in energy, especially in renewables [64]. The expansion of the renewable energy industry and grid development has the significant potential of reducing the Levelized Cost of Energy (cost of power produced over the lifetime of the system) by $10 \%$ [65]. Nathaniel et al. [66] identify renewable energy improves economic quality, and trade in Vietnam is not harmful to the environment. India has an impressive record of accomplishment in expanding electricity access through clean and renewable energy. India's strategies in building a robust renewable energy foundation can be shared with Vietnam, and such effective knowledge sharing ensures a win-win situation [67]. India currently employs $84 \mathrm{GW}$ of grid-connected renewable energy capacity forming $22.95 \%$ of total generation as of 2019; the target is set at $175 \mathrm{GW}$ from renewable sources by 2022.

In contrast, Vietnam has a $15.8 \%$ share of renewable sources as of 2019 [68]. India and Vietnam have the strategic advantage of an extensive coastline that can effectively generate offshore wind energy. The energy generated offshore is backed by steadier and consistent wind than onshore wind energy. At the same time, the noise and visual impacts are reduced [69]. The advancement in offshore wind is slow in India; countries with effective offshore wind growth have solid policies that can be studied to India's advantage and develop the sector [70, 71]. India has an ambitious target in offshore wind energy, $5 \mathrm{GW}$ by 2022 and $30 \mathrm{GW}$ by 2030 . The experience in onshore wind energy adds to the advantage when venturing into new unknown territories beyond the coastline. However, strategic ties with countries with equal ambitions in offshore wind energy generation play a critical role in achieving the goals of cleaner production [72]. According to estimates of the World Bank and the Danish Energy Agency, Vietnam can add $10 \mathrm{GW}$ to the global offshore wind energy mix by $2030[73,74]$. Active feed-in tariffs policy of $\$ 98 / \mathrm{MWh}$ in Vietnam's offshore wind has powered the rise of investments in the industry [15]. A collaborative strategy between India and Vietnam can improve the industry and make sustainable inroads to energy generation.

\section{Trade and Economic Cooperation: Opportunities and Challenges}

During the last two decades, India and Vietnam's bilateral political and economic relationship has upgraded to a strategic and comprehensive partnership. Such a time-honored development partnership has progressive contributions towards Vietnam's capacity-building and socio-economic development [62]. The focus of this 


\section{Power dynamics in Asia}

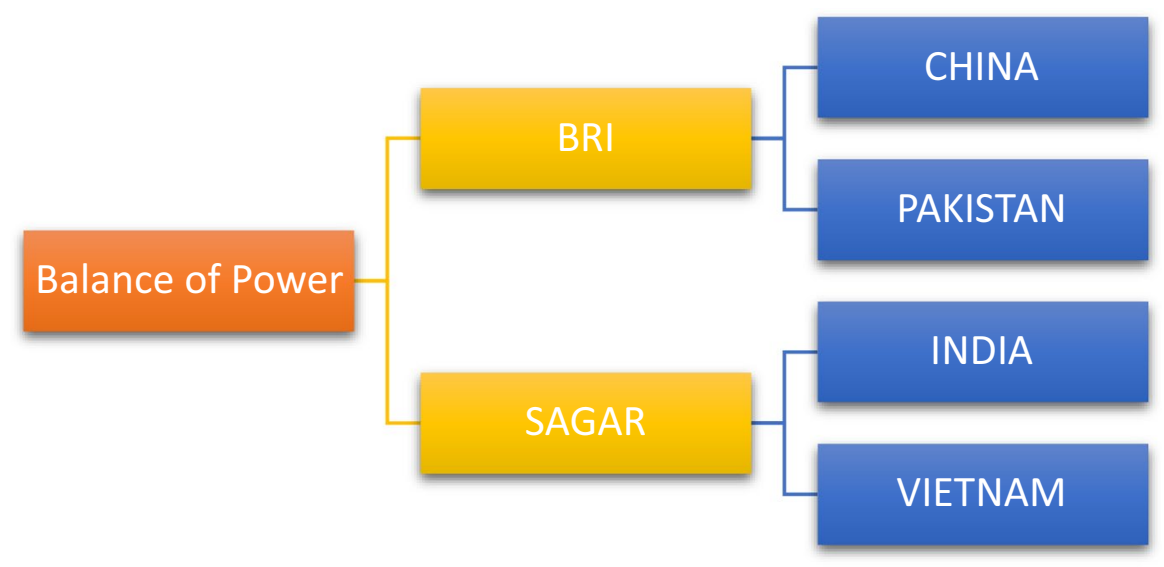

Fig. 1 Alliance and Counter Alliance in Indo-Pacific

relationship is reflected in shared political, economic, strategic, and diplomatic values, which have improved through the Government of India's policy navigation from "Look East" to "Act East" [38]. Moreover, the relationship between the two countries is marked by growing economic and commercial engagement, and India is now among the top ten trading partners of Vietnam. From US\$200 million in the year 2000, bilateral trade between India and Vietnam has seen steady growth over the years. Figure 1 [75] reflects the growth and trends (through LSTM Recurrent Neutral Network ${ }^{1}$ forecasting) in the economic cooperation between the two countries from 2010-2011 to 2029-2030. It shows that bilateral trade between India and Vietnam reached US $\$ 13.70$ billion in 2018-2019, with Indian exports to Vietnam amounting to US\$ 6.15 billion and Indian imports from Vietnam at US\$ 7.19 billion. In FY 2020-2021, for India, Vietnam was the 15th largest trading partner globally and the 4th largest within ASEAN, following Singapore, Indonesia, and Malaysia. For Vietnam, on the other hand, India was the 10th largest trading partner globally.

Using forecasting techniques, total trade between the two emerging economies will reach $\$ 21.54$ billion by the end of this decade. Besides the increase in trade volume between the two countries, the composition of trade has also changed in the last 20 years. Together with the investments channeled via other developing countries, Indian investments in Vietnam are projected at around US\$ 1.9 billion (Fig. 2). The Foreign Investment Agency of Vietnam estimated 299 Indian projects worth 909.5 million dollars as of April 2021 (see Fig. 3 [75]). This makes India rank amongst the

\footnotetext{
${ }_{1}$ Long Short-Term Memory (LSTM) is a type of Recurrent Neutral Network used in machine learning for training large architectures. It is designed to process sequential nature of the data [80]. We have used time series (sequence of data points that occur in successive order over some period of time) data of import and export of India and Vietnam to forecast till 2029-2030.
} 


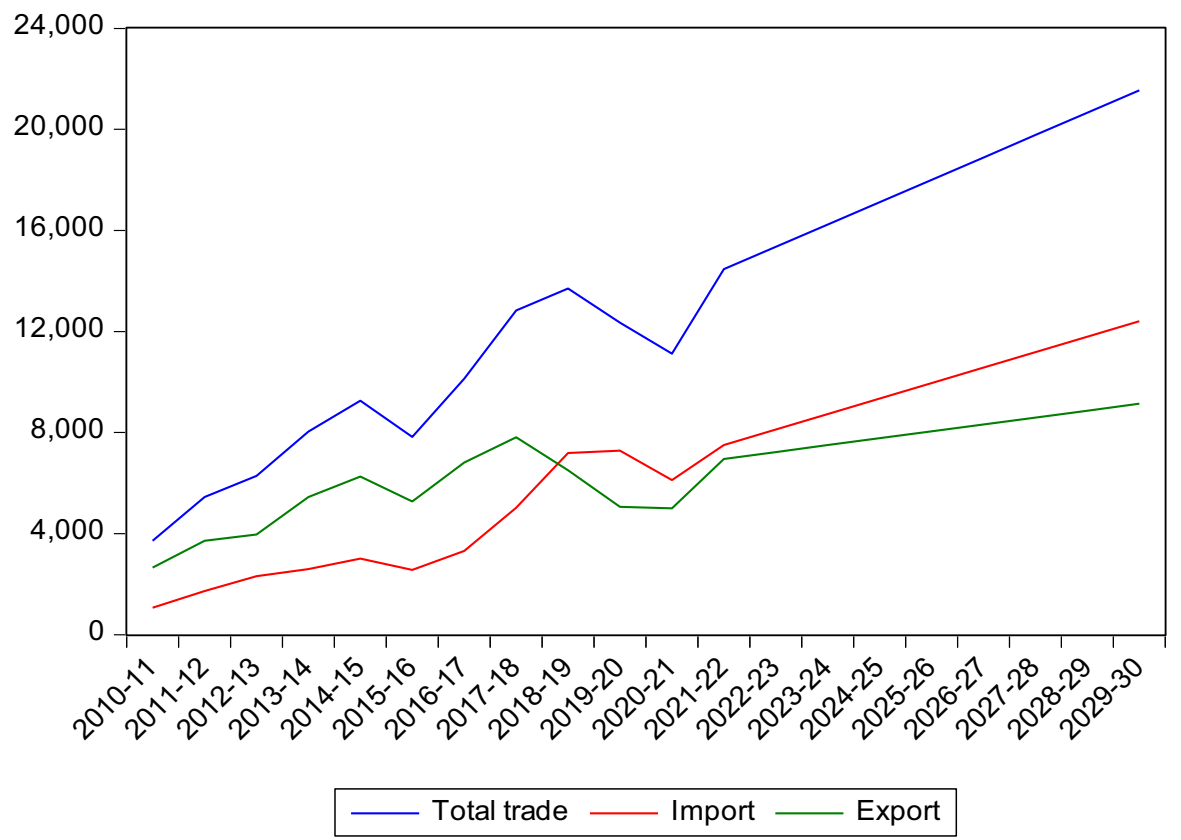

Fig. 2 Bilateral trade profile forecasted till 2030; vertical axis denotes trade in US\$ (million); horizontal axis is the year

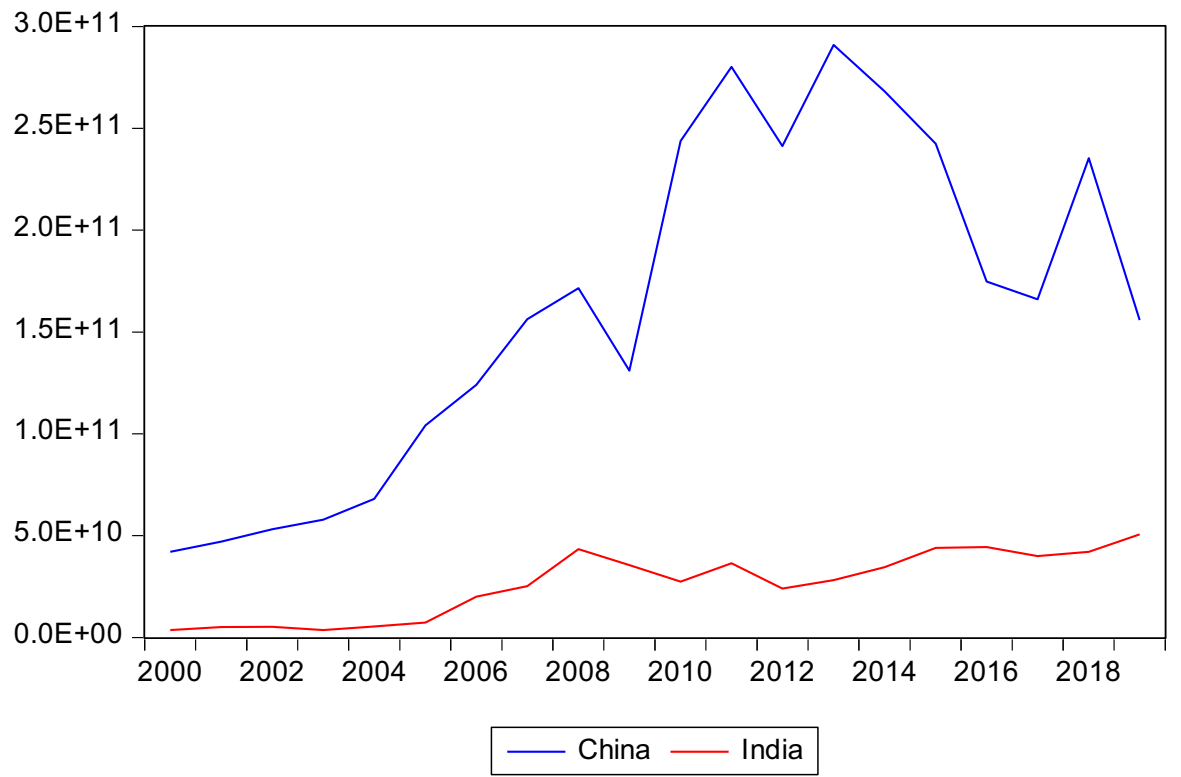

Fig. 3 Foreign direct investment, net inflows (current US\$) from India and China to Vietnam 2000-2019. Vertical axis denotes 4 foreign direct investment, net inflows (current US\$) from India and China to Vietnam; horizontal axis denotes year 
top 30 investors in Vietnam, still making room for much improvement. The composition of Indian investments is energy, mineral exploration, agro-processing, sugar, tea, coffee manufacturing, agro-chemicals, IT, and auto components.

On the other hand, Vietnam has only six investment projects in India, worth 28.55 million dollars. The composition of Vietnamese investments is in areas of pharmaceuticals, information technology, chemicals, and building materials. Figure 2 [76] shows that investment spending by China has gone down compared to India since 2015-2016 and significantly during the COVID-19 pandemic. This decline will open up new opportunities and create an investment window for India in the key sectors of Vietnam.

Enhancing sustainable trade and economic engagement between the two countries should be the elementary strategic objective, a fundamental component of the Comprehensive Strategic Partnership and an essential aspect for strengthening bilateral ties in the future. There is an urgent need to realize the potential to increase the volume of trade and diversification in its composition. More focus should be on goods and services that will help in operationalization and the realization of Sustainable Development Goals — social, economic, and environmental. Further, critical areas of investment should be explored to enhance new trade and investment opportunities in identified priority areas of cooperation like green energy, green infrastructure, sustainable tourism, energy conservation, textiles, footwear, pharmaceuticals, machine tools, agriculture and agro-products, chemicals, ICT, and other service sector industries. Both countries must cooperate to increase productivity, quantum, and content of science and technology in agricultural and green products. There is an urgent need to encourage two-way investment between the two countries to chalk out concrete plans to effectively implement the signed agreements to promote bilateral trade, including trade promotion and investment expansion measures. For sustainable cooperation and trade promotion, the bilateral relationship between the two countries should foster research and development in key areas with shared interests. This will lead to more economic advancement and help create employment opportunities in India and Vietnam.

\section{The Great Reset}

The COVID-19 pandemic has changed the traditional decision-making in the context of social, economic, and political zones [77]. The leaders are left with uncertainties in the short, medium, and long term; managing them becomes a significant concern. The great reset gives immense opportunity to rethink economic and social models that were unsustainable and kept a burden on SDG [78]. The opportunity for digital transformation will provide long-term value creation for India and Vietnam. Strategic ties in the form of technological advancements and the growing use of artificial intelligence can bring economic growth in the long run along with sustainable development [79].

Vietnam and India's relations should not be looked at only from the prism of "Vietnam is for India, what Pakistan is for China". Their relation should be futuristic and should be aligned with the United Nation's SDGs. There is considerable 
cooperation in multidimensional sectors for both countries to mutually nourish and contribute to regional peace and prosperity in Indo-Pacific. The great reset offers India and Vietnam a platform to build a robust cooperative mechanism based on mutual trust and confidence. Accompanied by the Intergovernmental Strategic Partnership Agreement, soft power tactics would benefit the cause of a counterbalance, as people's faith is what would take both these democracies forward to achieve a grand strategic- sustainable geopolitical balancing in Indo-Pacific in the twenty-first century.

\section{Conclusion}

China's emergence as a reliable economic and military power in Asia has shifted the balance of power in the region to be more Sino-centric. Other prominent players in Asia need to realign their policies to build bilateral and multilateral ties to create symmetry in the power balance. This paper suggests India-Vietnam's bilateral connections to realign itself according to UN Sustainable Development Goals to counterbalance China-Pakistan economic cooperation. China's Belt and Road Initiative connecting 70 countries from Asia to Africa and Europe intends to improve the infrastructure and trade; however, it comes across as a significant polluter and impact on sustainability. India's Vietnam policies should not only help to create a balance but also should include sustainable production and trade.

This paper fills the gap in the existing literature by suggesting key sustainable strategic moves in countering environmental degradation and rebalancing the IndoPacific. This collaboration between both nations would overlook sustainable consumption and trade practices in the region, as both are strategically significant in their geostrategic locations. Indo-Pacific is where the future of geopolitical rivalry will be played out, with players such as China, Japan, Australia, and the USA offering multiple platforms for economic and strategic superiority. It is here that the India-Vietnam alliance could provide a sustainable convergence to the littorals of Indo-Pacific, in line with the SDGs.

India's growing geopolitical interests in the Indo-Pacific are evident through its Mission SAGAR, helping India rebuild its image as an Asian big power. After the Comprehensive Strategic Partnership in 2016, bilateral ties between both countries have strengthened, following high-level diplomatic exchanges. It has witnessed a shared focus on regional security issues, trade, and commerce - with an increasing emphasis on energy import-export and knowledge sharing. However, the scope for widening these relations is abundant, and it needs to start with broadening the weakest link in India-Vietnam relations, i.e., the economic ties. This study indicates that the economic ties show positive signs, and despite the pandemic, India's investments in Vietnam are increasing, whereas China's investments are slopping down drastically. However, Chinese investments are still huge in Vietnam. Suppose India taps the "Great Reset" with new and innovative trade strategies by aligning its investments and trade according to UN Sustainable Development Goals. In that case, India can thus help sustainably rebalance the Asian power dynamics. 
The study is limited to bilateral ties between India and Vietnam, ignoring other strategic players in Southeast Asia such as Malaysia, the Philippines, and Indonesia, which calls for further future studies. This study is also limited to general recommendations, drawing a broad framework for sustainable bilateral ties between India and Vietnam. Further studies on the same area have scope for empirical analysis.

\section{References}

1. [1]S.S. Iyer, R. Mukhopadhyay, SD. Iyer, The Sino-Indian Geopolitics and Maritime Security of the Indian Ocean Region, Strateg. Anal. 45 (2021) 1-17. https://doi.org/10.1080/09700161.2020.18702 69.

2. [2]R. Aswani, S. Sajith, M.Y. Bhat, Is geopolitics a threat for offshore wind energy? A case of Indian Ocean Region, Environ. Sci. Pollut. Res. (2021). https://doi.org/10.1007/s11356-021-12779-z.

3. [3] O. Johnson, P. Choudhury, Maritime Theory Approach for Functional Effectiveness in the IndoPacific, India Q. 76 (2020) 444-460. https://doi.org/10.1177/0974928420936134.

4. [4]M. Beeson, Geoeconomics with Chinese characteristics: the BRI and China's evolving grand strategy, Econ. Polit. Stud. 6 (2018) 240-256. https://doi.org/10.1080/20954816.2018.1498988.

5. M. Duchâtel, AS Duplaix, Blue China: Navigating the Maritime Silk Road to Europe, Policy Br. (2018).

6. [6]M. Li, The Belt and Road Initiative: Geo-economics and Indo-Pacific security competition, Int. Aff. (2020). https://doi.org/10.1093/ia/iiz240.

7. [7]P. Uberoi, Problems and Prospects of the BCIM Economic Corridor, CHINA Rep. 52 (2016) 19-44. https://doi.org/10.1177/0009445515613868.

8. H.U. Khan, I. Khalid, New Delhi Response to Beijing "BRI" Project: A Lucid connection with Chinese \&quot;String of Pearls\&quot;, 2018.

9. T. Kuhlman, J. Farrington, What is Sustainability?, Sustain. . 2 (2010). https://doi.org/10.3390/ su2113436.

10. M. Al-Breiki, Y. Bicer, Comparative life cycle assessment of sustainable energy carriers including production, storage, overseas transport and utilization, J. Clean. Prod. 279 (2021). https://doi.org/10. 1016/j.jclepro.2020.123481.

11. A.A. Nassani, U. Awan, K. Zaman, S. Hyder, A.M. Aldakhil, M.M.Q. Abro, Management of natural resources and material pricing: Global evidence, Resour. Policy. 64 (2019). https://doi.org/10. 1016/j.resourpol.2019.101500.

12. [12]G. Alova, A global analysis of the progress and failure of electric utilities to adapt their portfolios of power-generation assets to the energy transition, Nat. Energy. 5 (2020) 920-927. https://doi. org/10.1038/s41560-020-00686-5.

13. [13]R. Selmi, J. Bouoiyour, S. Hammoudeh, Y. Errami, M.E. Wohar, The energy transition, Trump energy agenda and COVID-19, Int. Econ. 165 (2021) 140-153. https://doi.org/10.1016/j.inteco. 2020.12.010.

14. MNRE, Overview I Ministry of New and Renewable Energy, Government of India, (2021).

15. AWEA, Vietnam - Asia Wind Energy Association 2021, AWEA. (2021).

16. GWEC, Vietnam Wind Power 2021 | Global Wind Energy Council, (2021).

17. [17]V. Jha, "Soft law in a hard shell": India, International Rulemaking and the International Solar Alliance, Transnatl. Environ. Law. (2021). https://doi.org/10.1017/S2047102520000400.

18. [18]AG Baruah, How can India become a global leader in solar power generation?, Econ. Polit. Wkly. 54 (2019) 1-7.

19. [19]F. Urban, G. Siciliano, J. Nordensvard, China's dam-builders: their role in transboundary river management in South-East Asia, Int. J. Water Resour. Dev. 34 (2018) 747-770. https://doi.org/10. 1080/07900627.2017.1329138.

20. A. Soukhaphon, I.G. Baird, Z.S. Hogan, The impacts of hydropower dams in the Mekong river basin: A review, Water (Switzerland). 13 (2021). https://doi.org/10.3390/w13030265.

21. [21]M. Rosyidin, China's Strategic Culture and the Challenge of Security Management in the South China Sea Dispute, East Asia. 34 (2017) 133-145. https://doi.org/10.1007/s12140-017-9270-5. 
22. [22]RC De Castro, China's Belt and Road Initiative (BRI) and the Duterte Administration's Appeasement Policy: Examining the Connection Between the Two National Strategies, East Asia. 36 (2019) 205-227. https://doi.org/10.1007/s12140-019-09315-9.

23. NH. Phuoc, Compulsory dispute settlement entailing binding decisions under the UNCLOS: Its applicability to the case of Vietnam, J. East Asia Int. Law. 14 (2021) 35-54. https://doi.org/10. 14330/jeail.2021.14.1.02.

24. [24]Z. Daojiong, L. Gong, China and Southeast Asia in the 2000s: Tension management in the maritime space, Br. J. Polit. Int. Relations. 23 (2021) 248-261. https://doi.org/10.1177/1369148120 980944.

25. [25]J. YUAN, China's Belt and Road Initiative in South Asia and the Indian Response, Issues Stud. 55 (2019) 1940002. https://doi.org/10.1142/S1013251119400022.

26. [26]R.S. Aswani, Non-Traditional maritime security threats in the Indian Ocean Region: Policy alternatives, J. Public Aff. (2020). https://doi.org/10.1002/pa.2456.

27. M.S. Ahmad, F. Asmi, M. Ali, M.M. Rahman, S.M. Abbas, China-Pakistan Economic Corridor: In the context of 'String of Pearl Strategy, Int. J. Bus. Soc. Res. (2017). https://doi.org/10.18533/ijbsr. v7i8.1060.

28. [28]A. Ali, China Pakistan Economic Corridor: Prospects and Challenges for Regional Integration, Arts Soc. Sci. J. (2016). https://doi.org/10.4172/2151-6200.1000204.

29. [29]H.M. Javed, M. Ismail, CPEC and Pakistan: Its Economic Benefits, Energy Security and Regional Trade and Economic Integration, Chinese Polit. Sci. Rev. 6 (2021) 207-227. https://doi. org/10.1007/s41111-020-00172-z.

30. NS. Pyzhikov, E.S. Gushchin, Belt and Road Initiative: Interim results and challenges during the pandemic, World Econ. Int. Relations. 65 (2021) 42-51. https://doi.org/10.20542/ 0131-2227-2021-65-3-42-51.

31. [31]T. Mobley, The Belt and Road Initiative, Strateg. Stud. Q. 13 (2019) 52-72.

32. [32]J.E. Fanell, CHINA'S GLOBAL NAVAL STRATEGY AND EXPANDING FORCE STRU CTURE, Nav. War Coll. Rev. 72 (2019) 10-55.

33. [33]P.K. Jha, India-Vietnam relations: Need for enhanced cooperation, Strateg. Anal. (2008). https://doi.org/10.1080/09700160802404570.

34. NX. Binh, Vietnam-India economic ties: Challenges and opportunities since 2007, China Rep. (2016). https://doi.org/10.1177/0009445515627209.

35. [35]X.V. Vo, Vietnam-India Maritime Cooperation, Marit. Aff. (2017). https://doi.org/10.1080/ 09733159.2017 .1315888 .

36. [36]S. Sarma, India-Vietnam Relations through the Prism of the Indo-Pacific Concept, Strateg. Anal. (2020). https://doi.org/10.1080/09700161.2020.1809213.

37. [37]L.T.H. Nga, India-Vietnam Relations since September 2016: From the Symbolic to Practical Results, China Rep. (2017). https://doi.org/10.1177/0009445517711509.

38. [38]V.X. Vinh, India in Vietnam's Foreign Policy, Strateg. Anal. 44 (2020) 31-44. https://doi.org/ 10.1080/09700161.2020.1699997.

39. [39]C. Wang, Z. Miao, X. Chen, Y. Cheng, Factors affecting changes of greenhouse gas emissions in Belt and Road countries, Renew. Sustain. Energy Rev. 147 (2021) 111220. https://doi.org/10. 1016/j.rser.2021.111220.

40. S. Nazneen, X. Hong, N. Ud Din, B. Jamil, Infrastructure-driven development and sustainable development goals: Subjective analysis of residents' perception, J. Environ. Manage. 294 (2021). https://doi.org/10.1016/j.jenvman.2021.112931.

41. [41]Y. Wu, C. Chen, C. Hu, Does the Belt and Road Initiative Increase the Carbon Emission Intensity of Participating Countries?, China World Econ. 29 (2021) 1-25. https://doi.org/10.1111/cwe. 12374.

42. [42]D. Narain, M. Maron, H.C. Teo, K. Hussey, A.M. Lechner, Best-practice biodiversity safeguards for Belt and Road Initiative's financiers, Nat. Sustain. 3 (2020) 650-657. https://doi.org/10. 1038/s41893-020-0528-3.

43. [43]A.F. Pollard, The Balance of Power, J. Br. Inst. Int. Aff. 2 (1923) 51-64. https://doi.org/10.2307/ 3014464.

44. [44]R. Little, Deconstructing the Balance of Power: Two Traditions of Thought, Rev. Int. Stud. 15 (1989) 87-100.

45. [45]W. Zhou, M. Esteban, Beyond Balancing: China's approach towards the Belt and Road Initiative, J. Contemp. China. 27 (2018) 487-501. https://doi.org/10.1080/10670564.2018.1433476. 
46. [46]SD. Negara, S. Leo, Indonesia and China's Belt and Road Initiatives: Perspectives, Issues and Prospects, in: Indones. China's Belt Road Initiat., 2019. https://doi.org/10.1355/9789814818 605-002.

47. [47]W. Liu, M. Dunford, Inclusive globalization: unpacking China's Belt and Road Initiative, Area Dev. Policy. 1 (2016) 323-340. https://doi.org/10.1080/23792949.2016.1232598.

48. C. Yu, R. Zhang, L. An, Z. Yu, Has China's belt and road initiative intensified bilateral trade links between China and the involved countries?, Sustain. 12 (2020). https://doi.org/10.3390/SU121 76747.

49. [49]X. Gong, The Belt \& Road Initiative and China's influence in Southeast Asia, Pacific Rev. 32 (2019) 635-665. https://doi.org/10.1080/09512748.2018.1513950.

50. [50]J.-M.F. Blanchard, China's Maritime Silk Road Initiative (MSRI) and Southeast Asia: A Chinese 'pond' not 'lake' in the Works, J. Contemp. China. 27 (2018) 329-343. https://doi.org/10.1080/ 10670564.2018.1410959.

51. [51]R.W. Hu, China's 'One Belt One Road' Strategy: Opportunity or Challenge for India?, CHINA Rep. 53 (2017) 107-124. https://doi.org/10.1177/0009445517696619.

52. M.A. Karim, F. Islam, Bangladesh-China-India-Myanmar (BCIM) economic corridor: Challenges and prospects, Korean J. Def. Anal. 30 (2018) 283-302. https://www.scopus.com/inward/record.uri? eid=2-s2.0-85051718657\&partnerID=40\&md5=b8277b03a8fc7e471653eaadd0f1823a. Accessed 1 May 2021.

53. [53]C. Flint, C. Zhu, The geopolitics of connectivity, cooperation, and hegemonic competition: The Belt and Road Initiative, Geoforum. (2019). https://doi.org/10.1016/j.geoforum.2018.12.008.

54. [54]J.T. Jacob, China's Belt and Road Initiative: Perspectives from India, China World Econ. 25 (2017) 78-100. https://doi.org/10.1111/cwe.12215.

55. [55]N.T.P. Hoa, P.T. Nguyen, The Reception and Implementation of the Belt and Road Initiative in Vietnam, Strateg. Anal. 45 (2021) 128-143. https://doi.org/10.1080/09700161.2021.1893507.

56. [56]N. Di Lan, T.-M. Vu, The Sino-US-Vietnam Triangle in a Belt and Road Era, East Asia. 36 (2019) 229-241. https://doi.org/10.1007/s12140-019-09318-6.

57. P. Kumar, India Balancing China: Exploring Soft Balancing Through Indo-Pacific, Millenn. Asia. (2021) 0976399621998274. https://doi.org/10.1177/0976399621998274.

58. [58]T. Satake, J. Hemmings, Japan-Australia security cooperation in the bilateral and multilateral contexts, Int. Aff. 94 (2018) 815-834. https://doi.org/10.1093/ia/iiy028.

59. MEA, Government of India, 2021.

60. [60]J.S. Nye, Soft power: the evolution of a concept, J. Polit. Power. 14 (2021) 196-208. https://doi. org/10.1080/2158379X.2021.1879572.

61. [61]V. Solanki, India-Vietnam Defence and Security Cooperation, India Q. (2021). https://doi.org/ 10.1177/09749284211004982.

62. [62]R. Mishra, Vietnam's Regional Security Perceptions and Priorities: Role of India, India Q. (2021). https://doi.org/10.1177/09749284211004983.

63. [63]H.P. Ray, Sailing Ships, Naval Expeditions and 'Project Mausam,' India Q. 76 (2020) 411-424. https://doi.org/10.1177/0974928420936133.

64. [64]P.A. Nguyen, M. Abbott, T.L.T. Nguyen, The development and cost of renewable energy resources in Vietnam, Util. Policy. (2019). https://doi.org/10.1016/j.jup.2019.01.009.

65. A. Kies, B. Schyska, D. Thanh Viet, L. Von Bremen, D. Heinemann, S. Schramm, Large-Scale Integration of Renewable Power Sources into the Vietnamese Power System, in: Energy Procedia, 2017. https://doi.org/10.1016/j.egypro.2017.08.188.

66. [66]S. Nathaniel, O. Nwodo, G. Sharma, M. Shah, Renewable energy, urbanization, and ecological footprint linkage in CIVETS, Environ. Sci. Pollut. Res. (2020). https://doi.org/10.1007/ s11356-020-08466-0.

67. International Energy Agency, India 2020: Energy Policy Review, IEA. (2020).

68. IRENA, Renewable Capacity Statistics 2020, 2020.

69. [69]J. Park, B. Kim, An analysis of South Korea's energy transition policy with regards to offshore wind power development, Renew. Sustain. Energy Rev. 109 (2019) 71-84. https://doi.org/10.1016/j. rser.2019.04.031.

70. [70]S. Mani, T. Dhingra, Critique of offshore wind energy policies of the UK and Germany-What are the lessons for India, Energy Policy. 63 (2013) 900-909. https://doi.org/10.1016/j.enpol.2013. 09.058 .

71. [71]S. Mani, T. Dhingra, Offshore wind energy policy for India-Key factors to be considered, Energy Policy. (2013). https://doi.org/10.1016/j.enpol.2013.01.031. 
72. M. of N. and RE MNRE, Press Information Bureau Government of India Ministry of New and Renewable Energy, 2018.

73. IEA, IRENA, UNSD, World Bank, WHO, Tracking SDG 7: The Energy Progress Report, World Bank. (2020).

74. DEA, Vietnam I Energistyrelsen, DEA. (2021). https://ens.dk/en/our-responsibilities/global-coope ration/country-cooperation/vietnam. Accessed 26 June 2021.

75. World Bank, World Bank Open Data I Data, (2021).

76. Embassy of India, Embassy of India, Hanoi, Vietnam, (2021).

77. K. Schwab, T. Malleret, Covid-19: The Great Reset, 2020.

78. World Economic Forum, Digital Transformation: Powering the Great Reset, World Econ. Forum. (2020).

79. [79]M.A. Goralski, T.K. Tan, Artificial intelligence and sustainable development, Int. J. Manag. Educ. (2020). https://doi.org/10.1016/j.ijme.2019.100330.

80. Y. Tian, L. Pan, Predicting short-term traffic flow by long short-term memory recurrent neural network, in: Proc. - 2015 IEEE Int. Conf. Smart City, SmartCity 2015, Held Jointly with 8th IEEE Int. Conf. Soc. Comput. Networking, Soc. 2015, 5th IEEE Int. Conf. Sustain. Comput. Communic, Department of Electronic Engineering, Shanghai Jiao Tong University, Shanghai, China, 2015: pp. 153-158. https://doi.org/10.1109/SmartCity.2015.63.

Publisher's Note Springer Nature remains neutral with regard to jurisdictional claims in published maps and institutional affiliations. 